Supplement of

Source apportionment of carbonaceous aerosol using dual-carbon isotopes $\left({ }^{13} \mathrm{C}\right.$ and ${ }^{14} \mathrm{C}$ ) and levoglucosan in three northern Chinese cities during 2018-2019

\title{
Zhao et al.
}

Correspondence to: Zhenchuan Niu (niuzc@ieeas.cn) and Weijian Zhou (weijian@loess.llqg.ac.cn) 


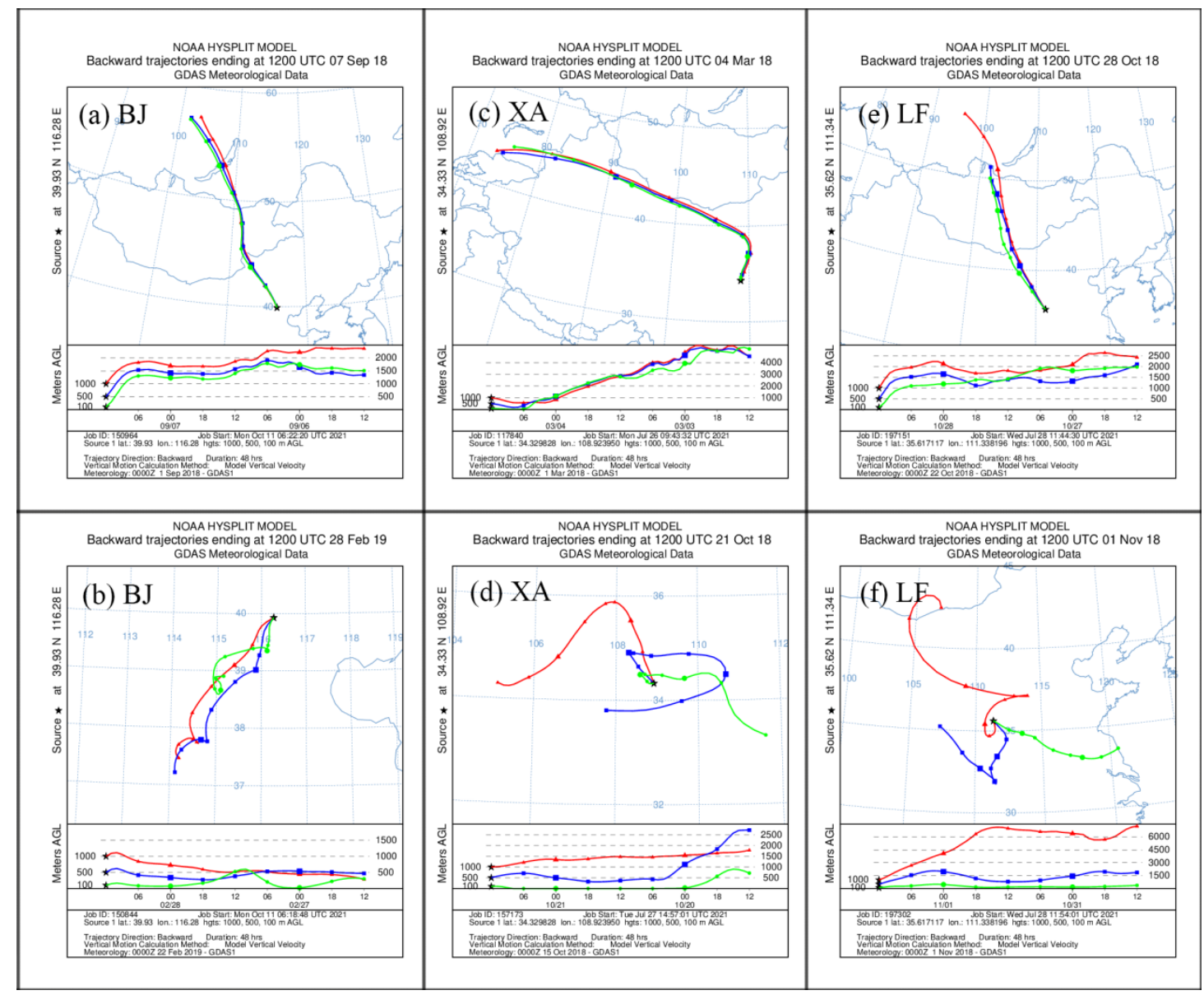

Fig. S1 48-h HYSPLIT air mass backward trajectories at 12:00 UTC on several days in Beijing (BJ), Xi'an (XA) and Linfen (LF), China (http://www.ready.noaa.gov/index.php). China adopts BJS (UTC+8). 


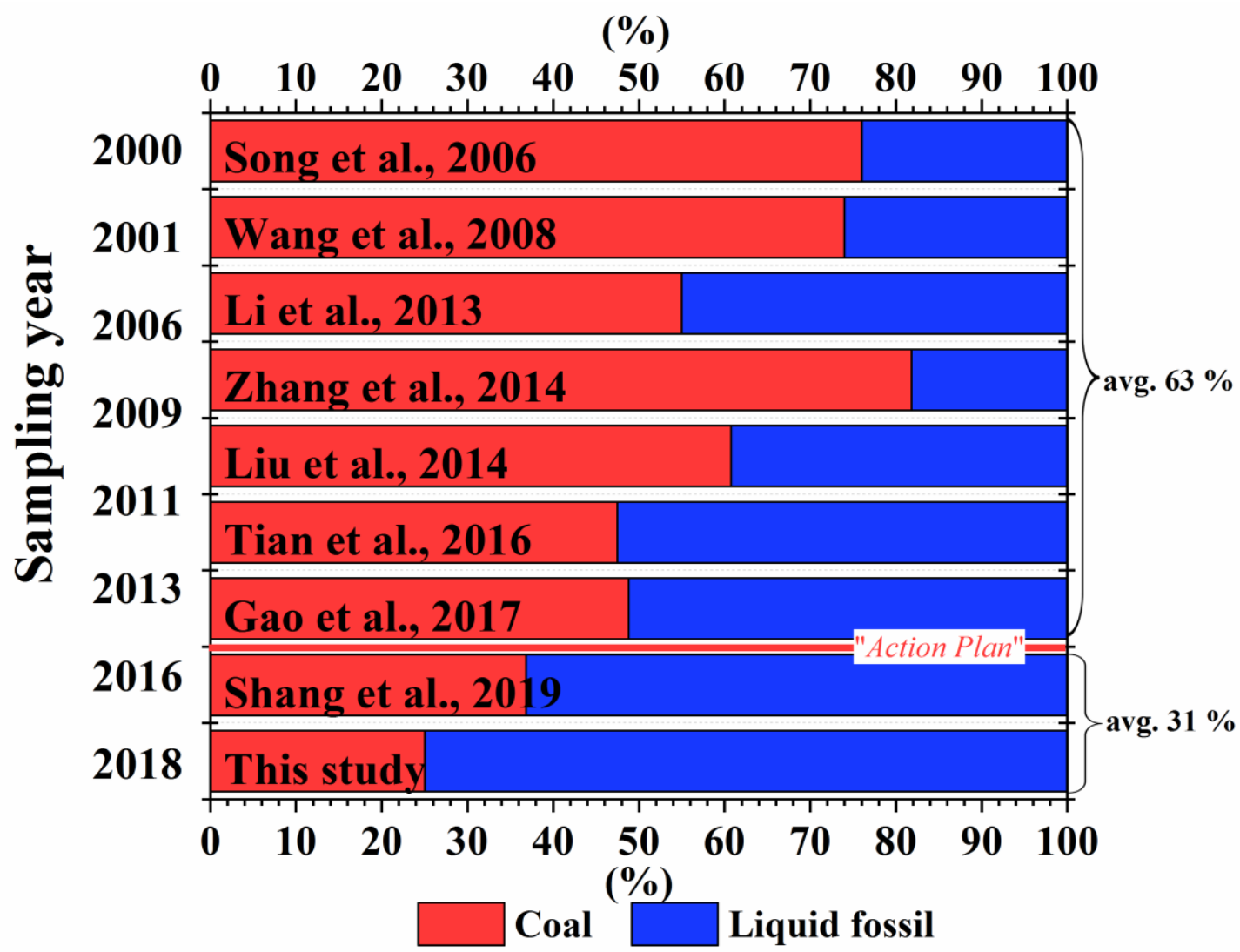

Fig. S2 Comparison of the proportions of coal combustion and liquid fossil combustion in aerosol in some studies in Beijing. The data has been converted. (Gao et al., 2018; Li et al., 2013; Liu et al., 2014; Shang et al., 2019; Song et al., 2006; Tian et al., 2016; Wang et al., 2008; Zhang et al., 2014). 


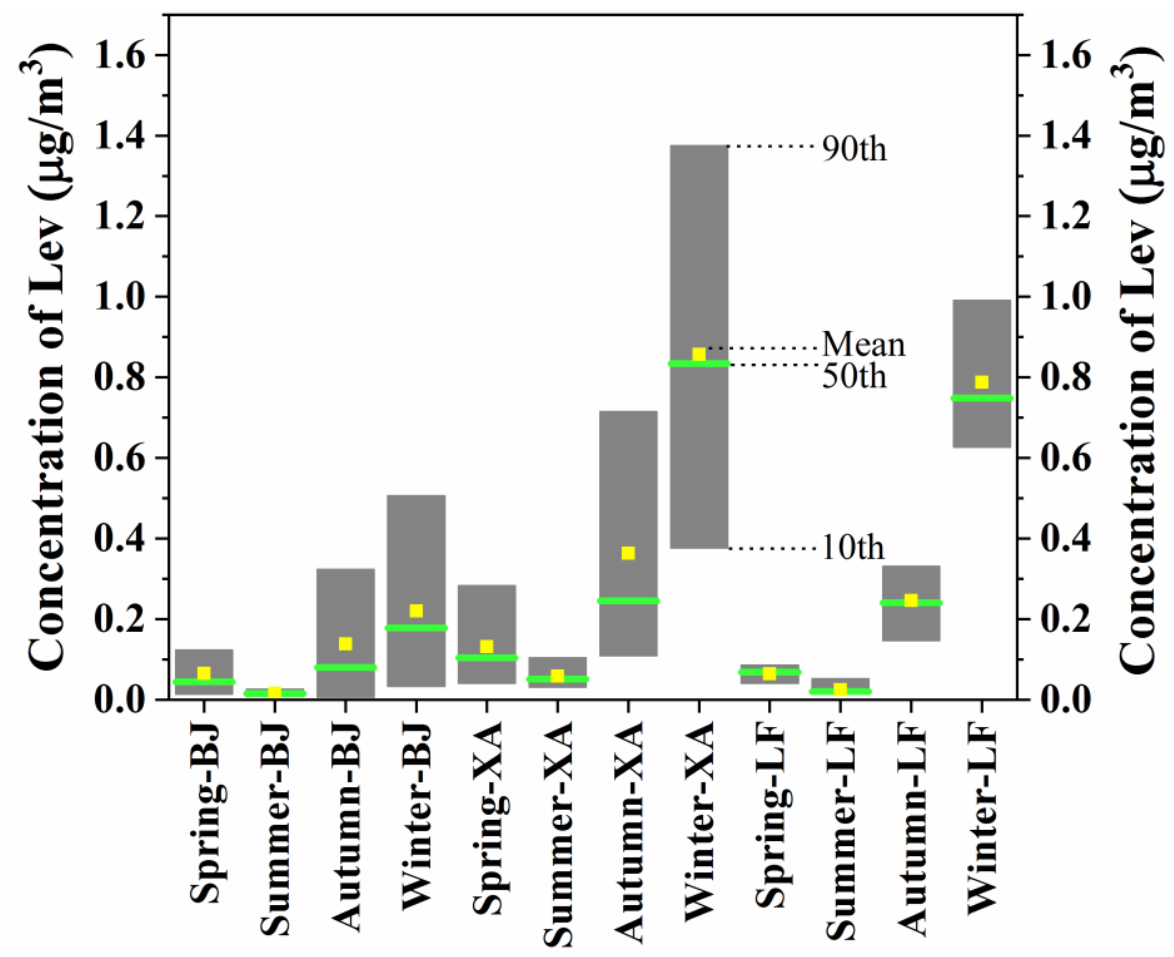

Fig. S3 Distribution of Lev concentration in carbonaceous aerosols at the sampling sites in Beijing (BJ), Xi'an (XA) and Linfen (LF). 


\section{References}

Gao, J., Wang, K., Wang, Y., Liu, S., Zhu, C., Hao, J., Liu, H., Hua, S., and Tian, H.: Temporal-spatial characteristics and source apportionment of PM2.5 as well as its associated chemical species in the Beijing-Tianjin-Hebei region of China, Environmental pollution, 233, 714-724, https://doi.org/10.1016/j.envpol.2017.10.123, 2018.

Li, X., Wang, Y., Guo, X., and Wang, Y.: Seasonal variation and source apportionment of organic and inorganic compounds in PM2.5 and PM10 particulates in Beijing, China, Journal of Environmental Sciences, 25, 741-750, https://doi.org/10.1016/S1001-0742(12)60121-1, 2013.

Liu, Z., Hu, B., Liu, Q., Sun, Y., and Wang, Y.: Source apportionment of urban fine particle number concentration during summertime in Beijing, Atmospheric Environment, 96, 359-369, https://doi.org/10.1016/j.atmosenv.2014.06.055, 2014.

Shang, J., Khuzestani, R., Tian, J., Schauer, J., Hua, J., Zhang, Y., Cai, T., Fang, D., An, J., and Zhang, Y.: Chemical characterization and source apportionment of PM2.5 personal exposure of two cohorts living in urban and suburban Beijing, Environmental Pollution, https://doi.org/10.1016/j.envpol.2018.11.076, 2019.

Song, Y., Zhang, Y., Xie, S., Zeng, L., Zheng, M., Salmon, L., Shao, M., and Slanina, S.: Source apportionment of PM2.5 in Beijing by positive matrix factorization, Atmospheric Environment, 40 , $1526-1537$, https://doi.org/10.1016/j.atmosenv.2005.10.039, 2006. 
Tian, S., Pan, Y., and Wang, Y.: Size-resolved source apportionment of particulate matter in urban Beijing during haze and non-haze episodes, Atmospheric Chemistry \& Physics, 16, 9405-9443, https://doi.org/10.5194/acp-16-1-2016, 2016.

Wang, H., Zhuang, Y., Wang, Y., Yuan, Y., and Zhuang, G.: Long-term monitoring and source apportionment of PM2.5/PM10 in Beijing, China, Journal of $\begin{array}{lll}\text { Environmental } & \text { Sciences, } & 20,\end{array}$ https://doi.org/10.1016/S1001-0742(08)62228-7, 2008.

Zhang, R., Jing, J., Tao, J., Hsu, S., Wang, G., Cao, J., Lee, C., Zhu, L., Chen, Z., and Zhao, Y.: Chemical characterization and source apportionment of PM2.5 in Beijing: seasonal perspective, Atmospheric Chemistry \& Physics, 13, 7053-7074, https://doi.org/10.5194/acp-14-175-2014, 2014. 